\title{
Psychic Phenomena Following Near-Death Experiences: An Australian Study
}

\author{
Cherie Sutherland, B.A. \\ University of New South Wales
}

ABSTRACT: This study examines the incidence of reports of psychic phenomena and associated beliefs both before and after the near-death experience (NDE). The near-death experiencers interviewed reported no more psychic phenomena before the NDE than the general population. There was a statistically significant increase following the NDE in the incidence of 14 of 15 items examined.

The near-death experience (NDE) occurs when a person is on the brink of death, or in some cases actually clinically dead, and yet survives to recount an intense, profoundly meaningful experience. Although there have been a number of studies conducted in other countries, to date there has been no detailed empirical study of the phenomenon in Australia.

In 1980-1981, a major survey by George Gallup, Jr. (1982) discovered that eight million Americans, or approximately five percent of the adult American population, have had what Gallup called a "verge-ofdeath" or "temporary death" experience with some sort of mystical encounter associated with the actual "death" event. In view of the

Ms. Sutherland was formerly a lecturer in the Department of Social Work, University of Sydney, and is currently a full-time doctoral student in the School of Sociology, University of New South Wales. Requests for reprints should be addressed to Ms. Sutherland at the School of Sociology, University of New South Wales, P.O. Box 1, Kensington, NSW 2033, Australia. 
major changes in values and beliefs that can occur as a result of these experiences, this is a figure of sociological significance and importance.

This paper describes the reports of paranormal events in the lives of 40 near-death experiencers interviewed as part of an ongoing study of aftereffects of NDEs.

\section{The Presence of Psychic Phenomena}

Most of the early studies of the NDE focused on the phenomenology of the experience itself. Bruce Greyson and Ian Stevenson (1980) reported the incidence of paranormal features occurring in the NDE itself.

Interest in the aftereffects of the NDE has grown in recent years. Kenneth Ring $(1980,1984)$ and Margot Grey (1985) described a range of aftereffects. Richard Kohr (1982) compared the psychic and psirelated experiences of near-death experiencers with two other groups within his sample, and Greyson (1983) specifically sought to compare the incidence of psychic phenomena in the lives of near-death experiencers before and after their NDEs. Both Kohr and Greyson used in their studies the questionnaire developed by John Palmer (1979) for his "Community Mail Survey of Psychic Experiences" among a general population of townspeople and students in Charlottesville, Virginia.

When examining my own data, it soon became clear that unless I could compare the incidence of psychic phenomena reported by my sample before their NDEs with the incidence in a general population, I would have no way of knowing whether the near-death experiencers I was interviewing could be considered "normal" before their NDEs or whether they were already unusually gifted psychically. In addition to Palmer's study (1979), those by Susan Blackmore (1984), Erlendur Haraldsson (1985), Kohr (1980), and the Roy Morgan Research Centre's "Australian Values Study Survey" (1983) provided data on the reported incidence of psychic experiences and associated beliefs among a general population.

Kohr (1982) analyzed data from a national survey of 547 members of the Association for Research and Enlightenment, a group having interests in parapsychological phenomena, dreams, and meditation. Although it is not possible to generalize from the results of that study to a wider population, it is possible to make comparisons among three categories within that special group: 84 near-death experiencers; 105 nonexperiencers, who had been close to death but had not had an NDE; and 358 others who had never been close to death. The results showed that the near-death experiencers reported more psychic and psi-related 
experiences than the nonexperiencers and others. Overall Kohr found a substantial difference between the near-death experiencers and the other two groups, which was statistically significant for all variables.

A similar pattern was shown in relation to changes in belief between near-death experiencers and nonexperiencers by a number of researchers (Ring, 1980, 1984; Flynn, 1986; Grey, 1985; Greyson and Stevenson, 1980). Michael Sabom (1982) found that belief in an afterlife increased dramatically among near-death experiencers, while there was no change in belief among nonexperiencers. Similarly, he found a marked decrease in fear of death among near-death experiencers, while among nonexperiencers 39 out of 45 reported no change and the remaining five reported an increase in fear of death.

As Kohr (1982) and Greyson (1983) suggested, there are at least three possible explanations for such differences:

1. near-death experiencers are more psychically sensitive prior to their NDEs,

2. near-death experiencers tend to focus more attention on psychic and psi-related experiences, or

3. there is actually an increase in the incidence of psychic and psi-related phenomena in the lives of people after an NDE.

\section{Method}

Subjects for this study were located by various means. Since my interest centered on the aftereffects of the NDE rather than on the experience itself, I wished to contact people who had had their experience more than two years earlier. It was therefore not appropriate to use hospital facilities as a source of respondents.

The 40 near-death experiencers interviewed for this study were located by the following means:

1. 3 subjects responded to my published articles on the subject, which included details of my own NDE (Sutherland, 19871988, 1988);

2. 5 subjects responded to public talks I gave;

3. 2 subjects responded to media interviews;

4. 11 subjects were recruited from a sample of experiencers already obtained by another researcher; and

5. 19 subjects were referred to me by a third party who had read my articles, heard me speak, or met me in some other context. 
I personally interviewed these 40 respondents, usually for $90 \mathrm{~min}$ utes, although at times I spent much longer with them. These interviews dealt with a wide range of issues, of which the incidence of paranormal phenomena in their lives was only one. No effort was made to verify the claims of psychic phenomena either before or since the NDE, apart from asking for explanations and examples of reported phenomena. I chose to use a semistructured or "focused" interview because of its flexibility and comparability. This style of interview, although time-consuming in preparation, administration, and collation of data afterwards, allowed for unanticipated answers by the interviewees and provided sufficient freedom to explore further any areas that I considered fruitful at the time. I was therefore able to collect on tape detailed data that emphasized the areas of greatest interest to each of the subjects.

Questions used in this study were loosely based on Ring's Psychic Experience Inventory (1984). However, because of the different format of my interviews, a number of his questions were omitted, and some additional questions were included. In most cases, Ring's explanation of each phenomenon was given before the question was asked. Overall my questioning was more open-ended than Ring's. For example, I began this section of my enquiry by describing what psychic phenomena refer to and asking whether before their NDEs these people had ever heard of such things. If so, I asked what their attitude to them was before their NDE, and then, what their attitude to them was after. I then asked if they ever had such an experience.

At this point I followed the lead of the interviewee, pursuing whatever experiences they spoke of and recording examples. Once their own examples had been concluded, I worked through my checklist, asking about any experience not so far mentioned. As a result of this approach, I was presented with a number of examples of experiences not explored in comparable studies listed in Table 2, such as clairaudience, automatic writing, visions of the future, predictions made during the NDE that have since come to pass, and being able to enter the body of another person.

I calculated percentages of subjects who had experienced each of four paranormal elements during their NDEs, and percentages of subjects who responded positively to questions concerning each of twelve paranormal experiences and four associated beliefs, both before and after the NDE.

I then performed chi-squared tests against the null hypothesis that there had been no change because of the NDE, and compared my results with studies of a general population to determine whether my 
sample had been "normal" or unusually psychically sensitive before their NDEs.

\section{Results}

\section{Subjects}

The 40 respondents included 13 men and 27 women. Their ages at the time of the NDE ranged from 7 to 58 years. Of the respondents, $25 \%$ were 19 years old or younger, $50 \%$ were 20 to 39 years old, and $25 \%$ were 40 to 59 years old. The number of years elapsed since their NDE ranged from 2 to 52 .

The NDEs in this sample occurred as a result of illness in 13 cases; surgery or postoperative complications in 9 cases; pregnancy, miscarriage, or childbirth in 8 cases; serious injury in 6 cases; drowning in 2 cases; poisoning in 1 case; and suicide in 1 case.

\section{Psychic Phenomena During the NDE}

Descriptions of psychic phenomena associated with the NDE itself were taken from the accounts of the experience given during the interviews. These are summarized in Table 1, where three items are compared with results from a study by Greyson and Stevenson (1980).

\section{Table 1}

Incidence of Paranormal Phenomena During the NDE

\begin{tabular}{|c|c|c|}
\hline Phenomenon & $\begin{array}{l}\text { Percent subjects } \\
\text { reporting phenomenon } \\
\text { in this study }\end{array}$ & $\begin{array}{l}\text { Percent subjects } \\
\text { reporting phenomenon } \\
\text { in Greyson and } \\
\text { Stevenson (1980) }\end{array}$ \\
\hline Out-of-body experience & 93 & 75 \\
\hline Presence or spirit & 48 & 49 \\
\hline $\begin{array}{l}\text { Extrasensory } \\
\text { perception }\end{array}$ & 45 & 39 \\
\hline $\begin{array}{c}\text { Transcendental } \\
\text { environment }\end{array}$ & 40 & - \\
\hline
\end{tabular}


For no items was there a significant difference between the percentages reported by Greyson and Stevenson and in my sample.

Out-of-body experiences were reported by 37 respondents ( $93 \%$ of my sample); 26 of these ( $70 \%$ ) claimed to have realized they were outside of their bodies when they saw their own physical body below them. Greyson and Stevenson (1980) found that $75 \%$ of their sample of 78 near-death experiencers similarly reported feeling or seeing themselves to be outside the physical body.

In addition, 19 respondents ( $48 \%$ of my sample) reported meeting some person, spirit, or presence either known or unknown to them; 8 of these (42\%) encountered a deceased relative. The others reported seeing angels, luminous beings, beautiful people, and/or a "being of light." One woman reported encountering numerous relatives who had died before her birth, and a dog who had been a childhood pet. Almost half (49\%) of Greyson and Stevenson's (1980) sample reported seeming to meet some person(s) not physically present.

Receiving some communication during the time they were out of their bodies was reported by 18 respondents (45\% of my sample). This communication ranged from simple messages such as "go back" to quite lengthy telepathic interchanges. One woman whose experience occurred during childbirth reported having been told telepathically that she had to go back since she was going to give birth to a son and would need to bring him up alone. Despite her wish to stay, she did go back, did give birth to a son, and one year later was deserted by her husband. Greyson and Stevenson (1980) found that 39\% of their sample reported apparent extrasensory experiences.

Finally, 16 respondents ( $40 \%$ of my sample) described a transcendental environment that they had visited. The most common description was of a very beautiful place: a garden, gentle rolling hills, green pastures, or a magnificent forest. Two people described a stream and one man reported being taken through a beautiful countryside past a stream, to a city, and into a building, called the archives, which held all knowledge. Once reaching this transcendental environment, all wished to stay but were either forced to return or more gently persuaded to do so.

\section{Increase in Psychic Phenomena After an NDE}

Percentages of my subjects reporting psychic phenomena are listed in Table 2, along with available comparisons with studies of general populations. The number of subjects varies for each item, as I have 


\section{Table 2}

Reports of Paranormal Experiences and Beliefs Before and After NDE

\begin{tabular}{|c|c|c|c|}
\hline Experience & $\begin{array}{l}\text { General } \\
\text { population } \\
\text { reporting } \\
\text { experience }\end{array}$ & $\begin{array}{l}\text { Subjects } \\
\text { reporting } \\
\text { experience } \\
\text { before NDE }\end{array}$ & $\begin{array}{c}\text { Subjects } \\
\text { reporting } \\
\text { experience } \\
\text { after NDE }\end{array}$ \\
\hline Clairvoyance $(n=37)$ & $38 \%(1)$ & $43 \%$ & $73 \%$ \\
\hline Telepathy $(\mathrm{n}=39)$ & $58 \%^{(1)}, 36 \%^{(2)}$ & $46 \%$ & $87 \%$ \\
\hline Precognition $(n=37)$ & - & $57 \%$ & $89 \%$ \\
\hline Déjà vu $(\mathrm{n}=37)$ & - & $76 \%$ & $84 \%$ \\
\hline $\begin{array}{l}\text { Supernatural rescue } \\
(\mathbf{n}=37)\end{array}$ & - & $38 \%$ & $78 \%$ \\
\hline Intuition $(\mathrm{n}=37)$ & - & $60 \%$ & $95 \%$ \\
\hline Guidance $(n=38)$ & $43 \%(3)$ & $37 \%$ & $92 \%$ \\
\hline $\begin{array}{l}\text { Dream awareness } \\
\quad(\mathbf{n}=37)\end{array}$ & $42 \%(1)$ & $43 \%$ & $76 \%$ \\
\hline $\begin{array}{l}\text { Out-of-body experience } \\
\quad(n=39)\end{array}$ & $14 \%^{(1)}, 12 \%^{(2)}$ & $18 \%$ & $51 \%$ \\
\hline Spirits $(n=38)$ & $27 \%^{(1)}, 26 \%^{(2)}$ & $24 \%$ & $68 \%$ \\
\hline Healing ability $(n=37)$ & - & $8 \%$ & $70 \%$ \\
\hline $\begin{array}{l}\text { Perception of auras } \\
(n=36)\end{array}$ & $5 \%^{(1)}$ & $14 \%$ & $47 \%$ \\
\hline $\begin{array}{l}\text { Beliefs } \\
\text { psychic phenomena } \\
(\mathrm{n}=36)\end{array}$ & $39 \%(4)$ & $44 \%$ & $97 \%$ \\
\hline $\begin{array}{l}\text { Reincarnation }(\mathrm{n}=33) \\
\text { Life after death }\end{array}$ & $31 \%(2), 32 \%^{(3)}$ & $39 \%$ & $79 \%$ \\
\hline $\begin{array}{l}\quad(n=34) \\
\text { Fear of death }(n=32)\end{array}$ & $\begin{array}{c}42 \%^{(2)}, 59 \%^{(3)} \\
-\end{array}$ & $\begin{array}{l}47 \% \\
78 \%\end{array}$ & $\begin{array}{r}100 \% \\
0 \%\end{array}$ \\
\hline $\begin{array}{l}\text { (1) United States } \\
\text { (2) Great Britain } \\
\text { (3)Australia } \\
\text { (4) Sweden } \\
\text { All differences between perc } \\
\text { except for déjà vu. }\end{array}$ & hofore & 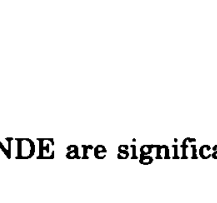 & at $p<.001$ \\
\hline
\end{tabular}

eliminated from analysis in each case those respondents who had not heard of, or thought about, various phenomena or beliefs by the time of the NDE. This affected particularly subjects who had had their NDEs as children. Chi-squared tests were used to estimate the probability of 
no change due to the NDE, except for healing ability, for which the Poissonian distribution was used because some cells had expected values less than 5 .

Significant increases following NDEs were found for all items except déjà vu. Greyson (1983) also found the increase in déjà vu not to be statistically significant. A number of respondents noted that the incidence of déjà vu was greater when they were children, although they still experienced the phenomenon now.

With regard to beliefs in reincarnation and life after death, the results tend to obscure the actual complexity of these beliefs. As the number of subjects shows, several people had not thought about either of these beliefs, or about death generally, before the NDE, and therefore were eliminated from the analysis for the purposes of this study. Of those remaining, 39\% said that they had believed in reincarnation before their NDE. This figure hides the fact that many of these believed in it only "a bit," whereas those who believed in it afterwards (79\%) tended to be more convinced. In addition, there were three respondents who did not believe in it before, but since the NDE now "tend to" believe.

Similarly, before the NDE $47 \%$ said that they believed in life after death. However, this particular belief generally concerned ideas of heaven, hell, and purgatory, notions that had been a part of their religious training as children. After the NDE $100 \%$ of my sample believed in life after death, and the beliefs they hold now are based on their own experiences and in many cases explicitly contradict the views held earlier. More than three-quarters (78\%) of my sample said that they had a fear of death before the NDE, whereas not one person among my sample has a fear of death now, and many laughed at the question.

Data presented in Table 2 show that percentages of "general population" answering positively to these items are comparable to percentages of my subjects before the NDE, evidence of the "normality" of my sample in this regard.

\section{Discussion}

I did not ask specifically whether my subjects focused more attention on psychic and psi-related activities after the NDE. However, it is evident from my data that there is a great variety of responses to these psychic phenomena. Some experiences seem to be absorbed into daily 
life and accepted as "normal" while others demand more attention because of their more disruptive nature.

For example, those who experience them seem to take clairvoyant (73\%) or precognitive (89\%) flashes in their stride, at times not even paying particular attention to them. On the other hand, those who have out-of-body experiences ( $51 \%$ ) could be said to focus on them, since they are not easy to ignore, whether engaged in voluntarily or occurring spontaneously. Of the phenomena most commonly experienced, $92 \%$ said that since the NDE they have felt more in touch with an inner source of wisdom and noted a very strong sense of being guided.

There are, however, cases among my sample whose response to an increase in psychic sensitivity has been extreme. There are four women, aged 43 to 65 , who before the NDE were school librarian, office worker, and housewives, who now work with their psychic gifts as healers. At the other extreme there are four men, aged 56 to 65 , who have tried to suppress their psychic capabilities because they feel so uncomfortable with them. This does not mean that they have been able to eliminate them entirely from their lives, but they have managed to stop certain activities, such as going out of the body and reading people's minds. The sex difference between these two extreme groups is worth noting and not entirely surprising, considering the socialization of men and women in Western industrial societies.

Overall, every person I interviewed was aware of the increase in psychic phenomena in their lives, although the degree of this increase varied, and two respondents stated that they had not connected the increase with their NDEs until the interview.

As a final question in my interview I always ask what each subject would say is the most significant change that has come about for him or her as result of the NDE. It is interesting to note that not one person mentioned the increase in psychic phenomena. Focusing, as I have in this paper, simply on this aspect therefore does not adequately reflect the breadth of changes in the priorities of these people. Neither does it accurately reflect their principle focus. Overwhelmingly their focus is on spiritual growth.

In conclusion, this study, with its present limitation of a small sample size, nevertheless demonstrates clearly the increased reports of psychic phenomena in the lives of near-death experiencers, confirming Greyson's findings (1983) with regard to those features the two studies have in common. The hypothesis that near-death experiencers were already more psychically gifted cannot be maintained in the face of comparisons with general populations. I hope with a larger sample to 
gain insight into the sociological significance of this increase in psychic phenomena in daily life.

\section{References}

Blackmore, S.J. (1984). A postal survey of OBEs and other experiences. Journal of the Society for Psychical Research, 52, 225-244.

Flynn, C.P. (1986). After the beyond: Human transformation and the near-death experience. Englewood Cliffs, NJ: Prentice-Hall.

Gallup, G., Jr. (1982). Adventures in immortality: A look beyond the threshold of death. New York, NY: McGraw-Hill.

Grey, M. (1985). Return from death. London, England: Arkana.

Greyson, B. (1983). Increase in psychic phenomena following near-death experiences. Theto, 11, 26-29.

Greyson, B., and Stevenson, I. (1980). The phenomenology of near-death experiences. American Journal of Psychiatry, 137, 1193-1196.

Haraldsson, E. (1985). Representative national surveys of psychic phenomena: Iceland, Great Britain, Sweden, U.S.A., and Gallup's multinational survey. Journal of the Society for Psychical Research, 53, 145-158.

Kohr, R. (1980). A survey of psi experiences among members of a special population. Journal of the American Society for Psychical Research, 74, 395-411.

$\mathrm{Kohr}, \mathrm{R}$. (1982). Near-death experience and its relationship to psi and various altered states. Theta, 10, 50-53.

Palmer, J. (1979). A community mail survey of psychic experiences. Journal of the American Society for Psychical Research, 73, 221-251.

Ring, K. (1980). Life at death: A scientific investigation of the near-death experience. New York, NY: Coward, McCann and Geoghegan.

Ring, K. (1984). Heading toward omega: In search of the meaning of the near-death experience. New York, NY: William Morrow.

Roy Morgan Research Centre. (1983). Australian values study survey [Machine-readable data file]. Melbourne, Australia: Australian Values Study Steering Committee (Producer). Canberra, Australia: Social Science Data Archives, The Australian National University (Distributor).

Sabom, M.B. (1982). Recollections of death: A medical investigation. New York, NY: Harper and Row.

Sutherland, C. (1987-1988). A reflection on the near-death experience. Australian Journal of Transpersonal Psychology, 7, 118-134.

Sutherland, C. (1988). The near-death experience: "Claiming life for the first time." Pallicom, 8(2), 18-23. 